\title{
Optimization of Material Removal Rate and Dimensional Errors in Subtractive Rapid Prototyping of Polycarbonate Material
}

\author{
SUTEJA The Jaya ${ }^{1, a}$ and HADIYAT Mochammad Arbi ${ }^{2, b}$ \\ ${ }^{1}$ Department of Manufacturing Engineering, University of Surabaya, Raya Kalirungkut, Surabaya, \\ Indonesia \\ ${ }^{1}$ Department of Industrial Engineering, University of Surabaya, Raya Kalirungkut, Surabaya, \\ Indonesia \\ ajayasuteja@staff.ubaya.ac.id, barbi@staff.ubaya.ac.id
}

Keywords: optimization, subtractive rapid prototyping, polycarbonate materials.

\begin{abstract}
None of the research found in the literature investigates and optimizes the subtractive rapid prototyping process parameters in order to fabricate polycarbonate material. This research is conducted to optimize the subtractive rapid prototyping process parameters of polycarbonate material in order to achieve the maximum material rate removal without exceeding the dimensional error value of $1 \mathrm{~mm}$, similar to the result of additive manufacturing. The response surface methodology is implemented in this research to optimized three process parameters, which are feed rate, step-over, and depth of cut. Two responses investigated in this research are material rate removal and dimensional error. The response optimizer is used to optimize the responses. The result shows that optimum material removal rate and dimensional error that can be achieved is $2.494 \mathrm{~mm}^{3} / \mathrm{s}$ and 0.97 $\mathrm{mm}$ respectively. A confirmation test experiment has been conducted to verify the optimization result.
\end{abstract}

\section{Introduction}

Polycarbonate material is a strong, tough, and transparent thermoplastic material that is used in various applications such as construction materials, automotive components, and tooling. Recently, its application is expanded for medical applications specifically for prosthetic products. Most of the prosthetic products are complex and customized for each patient. As a result, the feasible process to fabricate the product is by using rapid prototyping. Rapid prototyping is fast and automatic three dimensions physical modeling that uses computer aided design model as the input. Two methods in rapid prototyping are subtractive and additive rapid prototyping. Each of the method has their own advantages and disadvantages. Subtractive rapid prototyping method implements milling process to cut the raw material with tool that rotates in very high speed or high speed milling to produce the part. According to Toh, high speed milling refers to milling process with $10 \mathrm{~mm}$ tool diameter that is rotated in $10.000 \mathrm{rpm}$ [1]. Meanwhile, in the additive rapid prototyping method, the part is made by depositing materials layer by layer to build the shape of the part as explained by Islam, et, al. [2]. For a certain type of prosthetic products, the subtractive rapid prototyping is preferable to be implemented. The subtractive rapid prototyping is typically suitable to produce polycarbonate parts that require a specific surface roughness and dimensional accuracy. Therefore, the optimisation of subtractive rapid prototyping process parameters in fabricating polycarbonate materials is considered as a significant problem and needs to be tackled.

\section{Literature Review}

The main purpose of subtractive rapid prototyping is to achieve the required minimum surface roughness and dimensional error in the maximum material rate removal. Therefore, it is important to investigate the influence of the process parameters of subtractive rapid prototyping to the surface roughness, the dimensional error, and the material removal rate. In addition, it is also important to optimize the process parameters of subtractive rapid prototyping. This paper only describes the 
optimisation of subtractive rapid prototyping processes to achieve the maximum material removal rate and the minimum dimensional error.

Based on the literature, Nieminem, I., et. al. investigated the possibility to use subtractive rapid prototyping or high speed milling to fabricate a thin fin of polycarbonate material by changing the depth of cut and step-over [3]. However, Nieminem, I., et. al. did not investigate the influence of these parameters on the surface roughness and the dimensional error of the polycarbonate material [3]. Then, this research conducts a literature review on the influence of high speed milling process parameters on metal materials. In addition, studies by Albertí, M., et. al., Vivancos, J., Urbanski, J.P., Oktem, H., et al., The, J.S., et. al., Ma, W., et.al., Zeroudi, N. and Fontaine, M., and Shimana, K., et. al. show that material removal rate, surface roughness, and dimension error of a material are affected by interpolation type, tool holder type, controller of the machine, computer aided manufacturing software, physical and mechanical characteristics of the material, physical and mechanical characteristics of the tool, vibration, depth of cut, step-over, feed rate, cutting speed, and cut type [4, $5,6,7,8,9,10,11]$.

Based on the research by Suteja, T.J., a model had been developed to show the influence of the depth of cut, feed rate, and step-over on the vertical and horizontal surface roughness, vertical length error, horizontal length error, and depth error of polycarbonate material in subtractive rapid prototyping $[12,13]$. The proposed model shows that the increase of the step-over will increase the vertical and horizontal length errors. Second, the increase of the feed rate will decrease the vertical length error. Third, the increase of the depth of cut will decrease the vertical and horizontal length error value. Finally, the depth error will increase following the increase of all process parameters.

In order to optimize the process parameters, the expected dimensional error values need to be determined. The expected values are determined based on literature review. As additive rapid prototyping can also be used to fabricate a product made of polycarbonate, then previous research that investigate the surface roughness and dimensional error of part fabricated by using additive rapid prototyping are reviewed. Islam, et al. investigated the dimensional accuracy and repeatability of parts produced by 3D printing [2]. 3D printing is chosen because it provides faster production time, ease of use, and affordability. However, based on their research, it is found that the dimensional errors of the $3 \mathrm{D}$ printing process can achieve $0.153 \mathrm{~mm}$ [2]. Ippolito, R., et. al. compared five methods of additive rapid prototyping [14]. According to Ippolito, R., et. al., one of the additive rapid prototyping processes which is Stereolithography process can achieve the average dimensional error until $0.08 \mathrm{~mm}$ [14]. This research also describes that the highest dimensional accuracy for additive rapid prototyping process is achieved by using Fused Deposition Modeling. The achieved dimensional error of this process is $0.03 \mathrm{~mm}$. However, this process will generate higher surface roughness compared to other processes. Taft, et al. evaluated the accuracy of Stereolithography process by validating the accuracy of SLA skull models with a coordinate measurement device [15]. The research shows that the error of the process is small and acceptable for patient treatment. Meanwhile, Pal. et al. investigated the dimensional accuracy of several additive rapid prototyping processes, which are Stereolithography Apparatus, Fused Deposition Modeling, Selective Laser Sintering, Laminated Object Manufacturing, and 3-Dimensional Printing, in order to fabricate a pattern of sand and investment casting [16]. These processes are chosen because they can be used for fabricating tooling for intricate castings required in small numbers, with potentially shorter lead-time and lower cost compared to conventional machining. The result shows that the dimensional accuracy of the investigated processes is between 0.02 and $0.08 \mathrm{~mm}$. Brajlih, et al. evaluated the speed and accuracy of four different additive manufacturing processes, which are Poly Jet, Stereolithography, Laser Sintering, and Fused Deposition Modeling [17]. Based on the result, SLA process shows the best accuracy results compared to others.

The purpose of this research is particularly for investigating the subtractive rapid prototyping of a prosthetic product. He, Y., et al. implemented Scanning Printing Polishing Casting to fabricate a prosthetic product [18]. Based on their research, the fabrication method can achieve a low surface roughness and require low cost. However, the method requires more complex process and longer time. The research by Salmi, M., et al. shows that the average dimensional error of medical models made 
by the additive manufacturing is $0.2 \mathrm{~mm}$ to $0.93 \mathrm{~mm}$ [19]. Meanwhile, Shien, et al. investigated the accuracy of the injection molding of polycarbonate lenses [20]. The accuracy of the injection molding of the lenses is between $0.00212 \mathrm{~mm}$ to $0.0028 \mathrm{~mm}$. Even though the injection molding can achieve very high accuracy, it is not suitable for small volume production of prosthetic product. Therefore, the aim of this research is to optimize the process parameters in subtractive rapid prototyping to achieve the similar dimensional error of the additive manufacturing, which is maximum of $1 \mathrm{~mm}$, in the maximum material rate removal of polycarbonate material.

\section{Experimental work}

This research implements Response Surface Methodology to optimize the subtractive rapid prototyping process parameters. First, several mathematical models that relate the parameters and the responses are developed. Then, to validate the developed models, three residual tests, which are independence test, constant variance test, and normality test are conducted for each model.

In this research, the shape and the dimensions of the polycarbonate material specimen fabricated by using the subtractive rapid prototyping process is shown in Fig. 1. The shape and the dimension of the specimen are determined to make the dimensional error measurement possible. The subtractive rapid prototyping machine used in this research is Roland MDX 40 and a carbide solid square end mill with $5 \mathrm{~mm}$ diameter is used as the cutting tool. The machine is assisted by CAM Modela Player 4.0 software to generate the tool path. The software requires a three dimension model in STL format as the input to generate the tool path. In order to move the cutting tool, the software uses zigzag cut type.
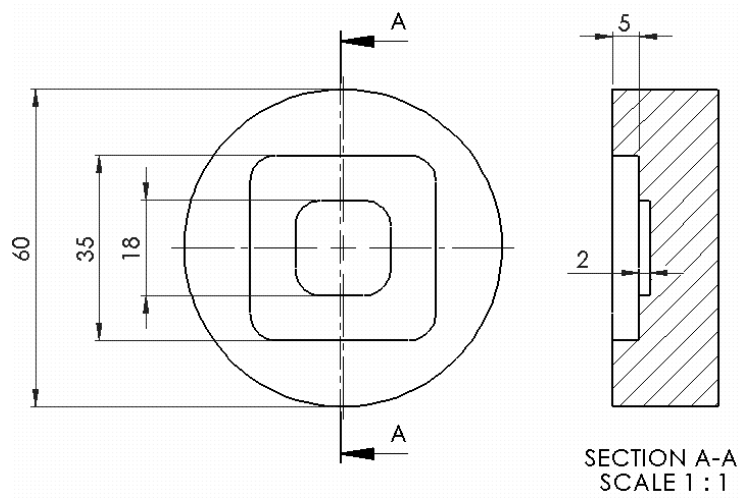

Fig. 1. The specimen (in $\mathrm{mm}$ ).

Roughing and finishing processes are applied in order to fabricate the specimen above. Each process requires different parameter values. The process parameters are determined based on the tools catalogue and interview with the expert. Table 1 shows the roughing parameter value of the subtractive rapid prototyping. For finishing process, three levels of value for depth of cut, feed rate, and step-over are determined. The value of each level for each parameter as shown in Table 2 is determined based on the machine specification, literature study, and the preliminary experiment. Meanwhile, the spindle and the entry speed for finishing process are $10000 \mathrm{rpm}$ and $4 \mathrm{~mm} / \mathrm{s}$ consecutively. The subtractive rapid prototyping is performed under dry operating condition.

Table 1. Parameter value for roughing.

\begin{tabular}{ll}
\hline Feed Rate & $: 12 \mathrm{~mm} / \mathrm{s}$ \\
\hline Entry Speed & $: 4 \mathrm{~mm} / \mathrm{s}$ \\
\hline Spindle Speed & $: 8500 \mathrm{rpm}$ \\
\hline Depth of Cut & $: 0.37 \mathrm{~mm}$ \\
\hline Step-over & $: 1 \mathrm{~mm}$ \\
\hline
\end{tabular}

Table 2. Parameter value for finishing.

\begin{tabular}{lccc}
\hline & Low & Middle & High \\
\hline Depth of Cut [mm] & 0.1 & 0.235 & 0.37 \\
\hline Feed Rate [mm/s] & 12 & 14.5 & 17 \\
\hline Step-over [mm] & 0.3 & 0.65 & 1 \\
\hline
\end{tabular}


In this research, three assumptions are taken. First, the polycarbonate material is assumed always homogeneous. Second, the cutting temperature is always constant. Third, the tool wear occurs after performing three roughing and finishing processes.

Two responses are investigated in this research, which are material rate removal and dimensional error. To calculate the material rate removal, the time needed to fabricate the specimen is measured by using a stopwatch. The dimensional error measurement is conducted at Industrial Metrology Laboratory of University of Surabaya. The dimensional error is determined based on the difference between the actual and the designed length of horizontal edge (parallel to the feed direction), the difference between the actual and the designed length of vertical edge (parallel to the step over direction), and the difference between the actual and the designed depth of the hole. The actual length and the depth are measured by using a caliper with $0.01 \mu \mathrm{m}$ of accuracy. After the measurement process, the measured data is analyzed by using MINITAB release 14 software.

\section{Results and discussion}

The first step in implementing the response surface methodology is designing and conducting the first order experiment. The first experiment involves all two level factors using $2^{3}$ factorial design with additional 5 center points. The design and result of the first order experiment are shown in Table 3.

Table 3. First order experiment results.

\begin{tabular}{ccccccccc}
\hline $\begin{array}{c}\text { Std } \\
\text { Orde } \\
\mathrm{r}\end{array}$ & $\begin{array}{c}\text { Run } \\
\text { Order }\end{array}$ & $\begin{array}{c}\text { Feed Rate } \\
{[\mathrm{mm} / \mathrm{s}]}\end{array}$ & $\begin{array}{c}\text { Step-ove } \\
\mathrm{r}[\mathrm{mm}]\end{array}$ & $\begin{array}{c}\text { Depth of } \\
\text { Cut [mm] }\end{array}$ & $\begin{array}{c}\text { Hor. Length } \\
\text { Error [mm] }\end{array}$ & $\begin{array}{c}\text { Ver. Length } \\
\text { Error [mm] }\end{array}$ & $\begin{array}{c}\text { Depth } \\
\text { Error }[\mathrm{mm}]\end{array}$ & $\begin{array}{c}\text { MRR } \\
{\left[\mathrm{mm}^{3} / \mathrm{s}\right]}\end{array}$ \\
\hline 11 & 1 & 14.50 & 0.65 & 0.235 & 0.05 & 0.57 & 0.00 & 1.221673 \\
\hline 13 & 2 & 14.50 & 0.65 & 0.235 & 0.05 & 0.61 & -0.01 & 1.220947 \\
\hline 2 & 3 & 17.00 & 0.30 & 0.100 & 0.04 & 0.28 & -0.01 & 0.266056 \\
\hline 12 & 4 & 14.50 & 0.65 & 0.235 & 0.03 & 0.67 & -0.04 & 1.222763 \\
\hline 7 & 5 & 12.00 & 1.00 & 0.370 & 0.06 & 1.00 & 0.02 & 2.607133 \\
\hline 9 & 6 & 14.50 & 0.65 & 0.235 & 0.04 & 0.72 & 0.01 & 1.220637 \\
\hline 3 & 7 & 12.00 & 1.00 & 0.100 & 0.09 & 1.03 & 0.00 & 0.704914 \\
\hline 5 & 8 & 12.00 & 0.30 & 0.370 & 0.05 & 0.36 & 0.01 & 0.801036 \\
\hline 10 & 9 & 14.50 & 0.65 & 0.235 & 0.05 & 0.73 & 0.00 & 1.217333 \\
\hline 6 & 10 & 17.00 & 0.30 & 0.370 & 0.03 & 0.29 & 0.03 & 0.983487 \\
\hline 1 & 11 & 12.00 & 0.30 & 0.100 & 0.04 & 0.40 & 0.01 & 0.215947 \\
\hline 4 & 12 & 17.00 & 1.00 & 0.100 & 0.09 & 1.07 & 0.03 & 0.868179 \\
\hline 8 & 13 & 17.00 & 1.00 & 0.370 & 0.09 & 1.02 & 0.02 & 3.213400 \\
\hline
\end{tabular}

The aim of this research is to determined the feed rate, step over, and depth of cut in subtractive rapid prototyping to achieve the maximum material rate removal of polycarbonate material and the dimensional error less than or equal to $1 \mathrm{~mm}$. Therefore, the mathematical models of vertical length error, horizontal length error, depth error, and material rate removal are developed and optimized.

Based on the residual tests, the first order models of vertical length error, horizontal length error, and depth error satisfies all the assumptions and can be used as the best prediction model. However, based on the lack of fit test, the first order model of material removal rate is not adequate as a linear regression model. Therefore, the first order model of material removal rate cannot be used as the prediction model of material removal rate. For that reason, the second order experiment for material removal rate, vertical length error, horizontal length error, and depth error must be conducted. The central composite design is used to determine the number of the second order experiment run. The design and result of the second order experiment is shown in Table 4. 
Table 4. Second order experiment results.

\begin{tabular}{|c|c|c|c|c|c|c|c|c|}
\hline $\begin{array}{c}\text { Std } \\
\text { Order }\end{array}$ & $\begin{array}{l}\text { Run } \\
\text { Order }\end{array}$ & $\begin{array}{c}\text { Feed } \\
\text { Rate } \\
{[\mathrm{mm} / \mathrm{s}]}\end{array}$ & $\begin{array}{l}\text { Step } \\
\text { Over } \\
{[\mathrm{mm}]}\end{array}$ & $\begin{array}{c}\text { Depth of } \\
\text { Cut } \\
{[\mathrm{mm}]} \\
\end{array}$ & $\begin{array}{c}\text { Hor. Length } \\
\text { Error } \\
{[\mathrm{mm}]} \\
\end{array}$ & $\begin{array}{c}\text { Ver. Length } \\
\text { Error } \\
{[\mathrm{mm}]} \\
\end{array}$ & $\begin{array}{l}\text { Depth } \\
\text { Error } \\
{[\mathrm{mm}]} \\
\end{array}$ & $\begin{array}{c}\mathrm{MRR} \\
{\left[\mathrm{mm}^{3} / \mathrm{s}\right]}\end{array}$ \\
\hline 18 & 1 & 14.5000 & 0.65000 & 0.235000 & 0.04 & 0.69 & 0.01 & 1.33510 \\
\hline 19 & 2 & 14.5000 & 0.65000 & 0.235000 & 0.04 & 0.68 & 0.00 & 1.22121 \\
\hline 10 & 3 & 18.7045 & 0.65000 & 0.235000 & 0.01 & 0.71 & 0.00 & 1.47727 \\
\hline 15 & 4 & 14.5000 & 0.65000 & 0.235000 & 0.03 & 0.69 & 0.03 & 1.22204 \\
\hline 20 & 5 & 14.5000 & 0.65000 & 0.235000 & 0.03 & 0.68 & 0.02 & 1.22152 \\
\hline 13 & 6 & 14.5000 & 0.65000 & 0.007958 & 0.01 & 0.65 & 0.02 & 0.04138 \\
\hline 14 & 7 & 14.5000 & 0.65000 & 0.462042 & 0.03 & 0.66 & 0.02 & 2.40249 \\
\hline 5 & 8 & 12.0000 & 0.30000 & 0.370000 & 0.01 & 0.38 & 0.01 & 0.79896 \\
\hline 11 & 9 & 14.5000 & 0.06137 & 0.235000 & 0.04 & 0.19 & 0.08 & 0.11581 \\
\hline 8 & 10 & 17.0000 & 1.00000 & 0.370000 & 0.09 & 1.56 & 0.05 & 3.21431 \\
\hline 6 & 11 & 17.0000 & 0.30000 & 0.370000 & 0.00 & 0.35 & 0.02 & 0.98372 \\
\hline 2 & 12 & 17.0000 & 0.30000 & 0.100000 & 0.03 & 0.41 & 0.00 & 0.26597 \\
\hline 9 & 13 & 10.2955 & 0.65000 & 0.235000 & 0.05 & 0.76 & 0.01 & 0.97840 \\
\hline 7 & 14 & 12.0000 & 1.00000 & 0.370000 & 0.07 & 1.55 & 0.01 & 2.61059 \\
\hline 12 & 15 & 14.5000 & 1.23863 & 0.235000 & 0.11 & 0.73 & 0.02 & 2.25131 \\
\hline 4 & 16 & 17.0000 & 1.00000 & 0.100000 & 0.06 & 1.56 & 0.02 & 0.86892 \\
\hline 3 & 17 & 12.0000 & 1.00000 & 0.100000 & 0.09 & $1 . .54$ & 0.02 & 0.70532 \\
\hline 16 & 18 & 14.5000 & 0.65000 & 0.235000 & 0.05 & 0.68 & 0.02 & 1.21149 \\
\hline 1 & 19 & 12.0000 & 0.30000 & 0.100000 & 0.02 & 0.38 & 0.03 & 0.21595 \\
\hline 17 & 20 & 14.5000 & 0.65000 & 0.235000 & 0.00 & 0.68 & 0.00 & 1.22183 \\
\hline
\end{tabular}

Based on the result shown in Table 4, the prediction model of material removal rate, vertical length error, horizontal length error, and depth error are shown in Eq. 1, Eq. 2, Eq. 3, and Eq. 4.

$$
\begin{aligned}
& \text { MRR }=0.462-0.0260 \times \mathrm{F}-0.901 \times \mathrm{S}-2.833 \times \mathrm{D}-0.00067 \times \mathrm{F}^{2}-0.162 \times \mathrm{S}^{2}-0.345 \times \mathrm{D}^{2} \\
& +0.0761 \times \mathrm{F} \times \mathrm{S}+0.2129 \times \mathrm{F} \times \mathrm{D}+7.804 \times \mathrm{S} \times \mathrm{D} \\
& \mathrm{E}_{\mathrm{ver}}=3.22-0.429 \times \mathrm{F}+1.11 \times \mathrm{S}-1.43 \times \mathrm{D}+0.0149 \times \mathrm{F}^{2}-0.035 \times \mathrm{S}^{2}+3.54 \times \mathrm{D}^{2}+0.004 \times \mathrm{F} \times \mathrm{S} \\
& -0.026 \times \mathrm{F} \times \mathrm{D}+0.19 \times \mathrm{S} \times \mathrm{D}
\end{aligned}
$$

$$
\begin{aligned}
& \mathrm{E}_{\text {hor }}=0.113-0.0051 \times \mathrm{F}-0.105 \times \mathrm{S}-0.160 \times \mathrm{D}+0.000040 \times \mathrm{F}^{2}+0.1319 \times \mathrm{S}^{2}-0.180 \times \mathrm{D}^{2} \\
& -0.00143 \times \mathrm{F} \times \mathrm{S}+0.0111 \times \mathrm{F} \times \mathrm{D}+0.132 \times \mathrm{S} \times \mathrm{D}
\end{aligned}
$$

$$
\mathrm{E}_{\text {depth }}=0.112+0.0068 \times \mathrm{F}-0.274 \times \mathrm{S}-0.483 \times \mathrm{D}-0.000664 \times \mathrm{F}_{2}+0.096 \times \mathrm{S}^{2}+0.063 \times \mathrm{D}^{2}
$$$$
+0.00857 \times \mathrm{F} \times \mathrm{S}+0.0296 \times \mathrm{F} \times \mathrm{D}+0.053 \times \mathrm{S} \times \mathrm{D}
$$

where MRR is material rate removal $\left[\mathrm{mm}^{3} / \mathrm{s}\right]$, Ever is vertical length error $[\mathrm{mm}], \mathrm{E}_{\text {hor }}$ is horizontal length error $[\mathrm{mm}], E_{\text {depth }}$ is depth error $[\mathrm{mm}], F$ is feed rate $[\mathrm{mm} / \mathrm{s}], S$ is step-over $[\mathrm{mm}]$, and $\mathrm{D}$ is depth of cut [mm].

The multiple response optimizer based on desirability approach is used to maximize the material rate removal and minimize the horizontal length and depth errors in order to achieve the value of vertical length error around $1 \mathrm{~mm}$ [21]. The result shows that the optimum condition achieved when the feed rate, step-over, and depth of cut are set in $12.84 \mathrm{~mm} / \mathrm{s}, 0.73 \mathrm{~mm}$, and $0.46 \mathrm{~mm}$ respectively. The maximum material removal rate achieved by implementing these parameters is $2.5 \mathrm{~mm}^{3} / \mathrm{s}$. The vertical length error, the horizontal length error, and the depth error are $1.00 \mathrm{~mm}, 0.03 \mathrm{~mm}$, and 0.006 mm respectively. 
In order to verify whether the predicted equations can be used to achieve the optimum dimensional errors and material rate removal, a confirmation test experiment is conducted. The result of the confirmation test experiment is shown in Table 5. As shown in Table 5, the average maximum material rate removal is $2.494 \mathrm{~mm}^{3} / \mathrm{s}$ and the average vertical length error, the horizontal length error, and the depth error $0.97 \mathrm{~mm}, 0.02 \mathrm{~mm}$, and $0.003 \mathrm{~mm}$ respectively. As, the result of the confirmation test experiment is similar to the result of the prediction model, then the result of the response optimizer can be used to estimate the optimum point for dimensional errors and material rate removal.

Table 5. Result of confirmation test experiment.

\begin{tabular}{ccccccc}
\hline $\begin{array}{c}\text { Feed } \\
\text { Rate } \\
{[\mathrm{mm} / \mathrm{rev}]}\end{array}$ & $\begin{array}{c}\text { Step } \\
\text { Over } \\
{[\mathrm{mm}]}\end{array}$ & $\begin{array}{c}\text { Depth of } \\
\text { Cut } \\
{[\mathrm{mm}]}\end{array}$ & $\begin{array}{c}\text { Hor. Length } \\
\text { Error } \\
{[\mathrm{mm}]}\end{array}$ & $\begin{array}{c}\text { Ver. Length } \\
\text { Error } \\
{[\mathrm{mm}]}\end{array}$ & $\begin{array}{c}\text { Depth } \\
\text { Error } \\
{[\mathrm{mm}]}\end{array}$ & $\begin{array}{c}\text { MRR } \\
{\left[\mathrm{mm}^{3} / \mathrm{s}\right]}\end{array}$ \\
\hline 12.84 & 0.73 & 0.46 & 0.00 & 0.94 & 0.000 & 2.4939 \\
\hline 12.84 & 0.73 & 0.46 & 0.03 & 1.00 & 0.015 & 2.4879 \\
\hline 12.84 & 0.73 & 0.46 & 0.03 & 0.97 & 0.015 & 2.5027 \\
\hline 12.84 & 0.73 & 0.46 & 0.03 & 0.98 & -0.020 & 2.4936 \\
\hline 12.84 & 0.73 & 0.46 & 0.01 & 0.96 & 0.005 & 2.4936 \\
\hline
\end{tabular}

\section{Conclusions}

This research implements the response surface methodology for optimizing the subtractive rapid prototyping parameters for polycarbonate material in order to achieve the maximum material rate removal of polycarbonate material and the dimensional error less than or equal to $1 \mathrm{~mm}$ at the same time. The optimized feed rate, step over, and depth of cut for the subtractive rapid prototyping are found to be $12.84 \mathrm{~mm} / \mathrm{s}, 0.73 \mathrm{~mm}$, and $0.46 \mathrm{~mm}$ respectively. By implementing these parameters, the achieved material removal rate is $2.494 \mathrm{~mm}^{3} / \mathrm{s}$ and the maximum dimensional error achieved is 0.97 mm.

\section{References}

[1] C.K. Toh, in: 'Surface topography analysis in high speed finish milling inclined hardened steel', Precision Engineering, Vol. 28, No. 4, (2004), pp.386-398.

[2] M. N. Islam, B. Boswell, and Pramanik, in: 'An investigation of dimensional accuracy of parts produced by three-dimensional printing', Proc. the World Congress on Engineering, Vol. 1, (2013).

[3] I. Nieminen, J. Paro, and V. Kauppinen, in: 'High-speed milling of advanced materials', Journal of Materials Processing Technology, Vol. 56, No. 1-4, (1996), pp.24-36.

[4] M. Albertí, J. Ciurana, C.A. Rodriguez, in: 'Experimental analysis of dimensional error vs. cycle time in high-speed milling of aluminium alloy', International Journal of Machine Tools and Manufacture, Vol. 47, No. 2, (2007), pp.236-246.

[5] J. Vivancos, C.J. Luis, L. Costa, J.A. Ort1z, in: 'Optimal machining parameters selection in high speed milling of hardened steels for injection moulds', Journal of Materials Processing Technology, Vol. 155, (2004), pp.1505-1512.

[6] J.P. Urbanski, P. Koshy, R.C. Dewes, D.K. Aspinwall, in: 'High speed machining of moulds and dies for net shape manufacture', Materials \& Design, Vol. 21, No. 4, (2000), pp.395-402.

[7] H. Oktem, T. Erzurumlu, H. Kurtaran, in: 'Application of response surface methodology in the optimization of cutting conditions for surface roughness', Journal of Materials Processing Technology, Vol. 170, No. 1-2, (2005), pp.11-16. 
[8] J.S. The, et. al. in: 'Optimasi proses pemesinan milling fitur pocket material baja karbon rendah menggunakan response surface methodology', Jurnal Ilmiah Teknik Mesin Universitas Kristen Petra, Vol. 10, No. 1, (2008), pp.1 -7.

[9] W. Ma, G. He, L. Zhu, and L. Guo, in: 'Tool deflection error compensation in five-axis ball-end milling of sculptured surface', The International Journal of Advanced Manufacturing Technology, Vol. 84, No. 5-8, (2016), pp.1421-1430.

[10] N. Zeroudi, and M. Fontaine, in: 'Prediction of tool deflection and tool path compensation in ball-end milling', Journal of Intelligent Manufacturing, Vol. 26, No. 3, (2015), pp.425-445.

[11] K. Shimana, E. Kondo, H. Karashima, M. Nakao, and S. Yamashita, in: 'An approach to real-time compensation of machining error using deflection of tool estimated from cutting forces in end-milling process', Journal of Advanced Mechanical Design, Systems, and Manufacturing, Vol. 10, No. 2, (2016), pp.1-10.

[12] T.J. Suteja, in: 'The influence of depth of cut, feed rate and step-over on surface roughness of polycarbonate material in subtractive rapid prototyping', Lecture Notes in Electrical Engineering, Vol. 365, (2016), pp.409-414.

[13] T.J. Suteja, in: 'The influence of depth of cut, feed rate, and step-over on dimensional accuracy in subtractive rapid prototyping of polycarbonate material', IOP Conf. Ser.: Mater. Sci. Eng., Vol. 187, (2017), pp.012033.

[14] R. Ippolito, L. Iuliano and Gatto in: 'A benchmarking of rapid prototyping techniques in terms of dimensional accuracy and surface finish', CIRP Annals-Manufacturing Technology, Vol. 44, No. 1, (1995), pp.157-160.

[15] R.M. Taft, S. Kondor, and G.T. Grant, in: 'Accuracy of rapid prototype models for head and neck reconstruction', The Journal of prosthetic dentistry, Vol. 106, No. 6, (2011), pp.399-408.

[16] D.K. Pal. and B. Ravi, in: 'Rapid tooling route selection and evaluation for sand and investment casting', Virtual and Physical Prototyping Journal, Vol. 2, No. 4, (2007), pp.197-207.

[17] T. Brajlih, B. Valentan, J. Balic and I. Drstvensek, in: 'Speed and accuracy evaluation of additive manufacturing machines', Rapid prototyping journal, Vol. 17, No. 1, (2011), pp.64-75.

[18] Y. He, G.H. Xue, and J.Z. Fu, in: 'Fabrication of low cost soft tissue prostheses with the desktop 3 D printer', Scientific reports, Vol. 4, (2014), pp.6973.

[19] M. Salmi, et al. in: 'Accuracy of medical models made by additive manufacturing (rapid manufacturing)', Journal of Cranio-Maxillofacial Surgery, Vol. 41, No. 7, (2013), pp.603-609.

[20] J.Y. Shieh, L.K. Wang, and S.Y. Ke, in: 'A feasible injection molding technique for the manufacturing of large diameter aspheric plastic lenses', Optical review, Vol. 17, No. 4, (2010), pp.399-403.

[21] L.V. Candioti, M.M. De Zan, M.S. Camara, and H.C. Goicoechea, in: 'Experimental design and multiple response optimization. Using the desirability function in analytical methods development', Talanta,Vol. 124, (2014) pp.123-138. 